\title{
Capacity Choice in a Quantity-Setting Mixed Duopoly with Network Effects
}

\author{
Yasuhiko Nakamura \\ College of Economics, Nihon University, Tokyo, Japan \\ Email: Yasuhiko.r.nakamura@gmail.com
}

Received October 28, 2013; revised November 28, 2013; accepted December 5, 2013

Copyright (c) 2014 Yasuhiko Nakamura. This is an open access article distributed under the Creative Commons Attribution License, which permits unrestricted use, distribution, and reproduction in any medium, provided the original work is properly cited. In accordance of the Creative Commons Attribution License all Copyrights (C) 2014 are reserved for SCIRP and the owner of the intellectual property Yasuhiko Nakamura. All Copyright (C) 2014 are guarded by law and by SCIRP as a guardian.

\section{ABSTRACT}

This paper explores the capacity choice for a public firm that is a social welfare-maximizer and a private firm that is an absolute profit-maximizer in the context of a quantity-setting mixed duopoly with a simple mechanism of network effects where the surplus that a firm's client gets increases with the number of other clients of the firm. In this paper, we show that the social welfare-maximizing public firm chooses under-capacity irrespective of both the degree of product differentiation and strength of network effects, whereas the absolute profit-maximizing private firm chooses over-capacity irrespective of both the degree of product differentiation and strength of network effects, which is strikingly different from the results on the capacity choice problems for public and private firms obtained in price-setting mixed duopolistic markets in the existing literature.

\section{KEYWORDS}

\section{Mixed Duopoly; Quantity Competition; Network Effects; Capacity Choice}

\section{Introduction}

This paper investigates the capacity choice issue for a public firm that is a social welfare-maximizer and a private firm that is an absolute profit-maximizer in the context of a quantity-setting mixed duopoly with network effects where the surplus that a firm's client gets increases with the number of other clients of the firm. ${ }^{1}$ Similar to the works on the capacity selection issues in private oligopolies composed of private firms only, such as the seminal works of Dixit [1] and Brander Spencer [2], studies exist in the context of mixed oligopolistic markets composed of both public and private firms that broadly investigate the capacity choice problems ${ }^{2}$. Most

\footnotetext{
${ }^{1}$ Similar to a private duopoly composed of private firms only, since the network effect such that a firm's client gets surplus increases along with the number of other clients of the firm can be observed in the representative real world mixed oligopolistic industries including the airline, rail, telecommunications, natural gas, electricity, steel, and overnight-delivery, as well as in the services including banking, home loans, health care, life insurance, hospitals, broadcasting, and education, it is important to consider the capacity choice problems of both the public and private firms in a mixed duopoly with network effects.
}

recently, Nakamura [7] investigated the capacity choice problems in a price-setting mixed duopoly with network effects in the fashion of Katz and Shapiro [8] and Hoernig [9], and showed that a public firm chooses over-capacity, whereas the difference between the quantity and capacity levels of a private firm strictly depends on both the degree of product differentiation and strength of network effects. ${ }^{3}$ In this paper, in a quantity-setting mixed duopoly with network effects, we confirm the robustness of the results of the difference between the quantity and

${ }^{2}$ Nishimori and Ogawa [3] is a seminal paper that considered the capacity choice problems in the context of a mixed duopolistic market using the approach à la Horiba and Tsutsui [4], and they showed that in a quantity-setting game with homogeneous goods, a public firm chooses under-capacity while a private firm chooses over-capacity, which is different from the result found in the existing literature on private oligopolistic markets. Subsequently, Ogawa [5] and BárcenaRuiz and Garzón [6] extended the model introduced in Nishimori and Ogawa [3] to quantity-setting and price-setting mixed markets with differentiated goods, respectively.

${ }^{3}$ The area of the demand parameter considered in this paper corresponds to that wherein the goods produced by both the social welfaremaximizing public firm and the absolute profit-maximizing private firm are substitutable, which is similar to the price-setting mixed duopoly with network effect considered in Nakamura [7]. 
capacity levels of both public and private firms in the case of price-setting mixed duopolies obtained by Nakamura [7]. More precisely, we ascertain whether or not the differences between the output and capacity levels of both the public firm and private firm depend on the strength of network effects à la Katz and Shapiro [8] and Hoernig [9] and the degree of product differentiation in a quantity-setting mixed duopoly ${ }^{4}$.

In this paper, we show that in quantity competition with the network effects à la Katz and Shapiro [8], Hoernig [9], and Nakamura [7], a social welfare-maximizing public firm chooses under-capacity irrespective of the degree of product and strength of network effects, whereas an absolute profit-maximizing private firm chooses over-capacity irrespective of the degree of product differentiation and strength of network effects, which is strikingly different from the results in price competition obtained in Nakamura [7]. The intuition behind the result that the difference between the quantity and capacity levels of a social welfare-maximizing firm is always positive can be explained as follows: In quantity competition with network effects, regardless of the degree of product differentiation and strength of network effects, a public firm attempts to increase the quantity level of the rival private firm in order to enhance social welfare. Then public firm attempts to increase the quantity level of the private firm through the following two effects: 1) the negative association between the quantity of the private firm and its own capacity level and 2) the combination of the strategic substitutability between the capacity levels of both the firms and the positive association between the quantity and capacity levels of the private firms. From the two effects, the public firm has a strong incentive to refrain from increasing its own capacity level, implying that a public firm always chooses under-capacity irrespective of the degree of product differentiation and strength of network effects. On the contrary, in the quantity competition, the private firm has a strong incentive to use its capacity level strategically in order to expand its market share, since it must compete with the social welfare-maximizing public firm that is a strong competitor in the market. More precisely, the private firm attempts to increase its quantity level by raising its own capacity level through the following two effects: 1) the negative association between the quantity level of the public firm and its own capacity level, and 2) the combination of the strategic relation between the capacity levels of both the firms and the positive association between the quantity and capacity levels of the private firm. Consequently, the private firm always chooses over-capacity irrespective of the degree of product differentiation and the strength of network effects.

The remainder of this paper is organized as follows. In Section 2, we formulate a quantity-setting mixed duopolistic model with capacity choice of both the social welfare-maximizing public firm and the absolute profitmaximizing private firm with network effects à la Katz and Shapiro [8] and Hoernig [9]. In Section 3, we consider the difference between the quantity and capacity levels of both the public firm and private firm. Section 4 concludes the paper with several remarks.

\section{Model}

We formulate a quantity-setting competition model in a mixed duopoly with the capacity choice of both a public firm and a private firm and with an additional term that reflects network effects in the fashion of Katz and Shapiro [8] and Hoernig [9] ${ }^{5}$.

We assume that firm 0 is a public firm that is a welfare-maximizer whereas firm 1 is a private firm that is an absolute profit-maximizer. Similar to Hoernig [9], firm $i$ faces a linear demand of the following form:

$$
q_{i}\left(p_{0}, p_{1} ; y_{0}, y_{1}\right)=a+n y_{i}-p_{i}+b p_{j}, \quad i=0,1 ; i \neq j,
$$

where $a>0$ and $b \in(0,1)$ are demand parameters. $n \in[0,1)$ indicates the strength of network effects, and $y_{i}$ is the consumers' expectation on firm $i$ 's equilibrium market share. This specification implies the following inverse demand functions for positive demand:

$$
p_{i}\left(q_{0}, q_{1} ; y_{0}, y_{1}\right)=\left[a(1+b)-q_{i}-b q_{j}+n y_{i}+b n y_{j}\right] /\left(1-b^{2}\right), \quad i, j=0,1 ; i \neq j .
$$

As explained in Hoernig [9], the above demand system can be derived from the following quasi-linear concave utility function of a representative consumer:

\footnotetext{
${ }^{4}$ In another strand of research on the capacity choice problems of public and private firms in a mixed duopoly, Tomaru et al. [10] analyzed the influence of the separation between ownership and management in the fashion of Fershtman and Judd [11], Sklivas [12], and Vickers [13] on the difference between the output and capacity levels of both the public and the private firms and the changes therein before and after privatization of the public firm. Furthermore, more recently, Nakamura and Saito [14] and Nakamura and Saito [15] investigated the capacity choice of a public firm that is a social welfare-maximizer and a private firm that is a relative profit-maximizer in the context of quantity-setting and price-setting mixed duopolies, respectively; their most important contribution in these two papers is to show that even though the relation between the goods produced by the two firms is restricted to being substitutable, the difference between the output and capacity levels of the private firm can change in accordance with the degree of importance of its relative performance.

${ }^{5}$ In the model employed in this paper, the parameters are $a, b, c$, and $n$. The economic meanings of such parameters are given in the following body of this paper.
} 


$$
U\left(q_{0}, q_{1} ; y_{0}, y_{1}\right)=m+\frac{a\left(q_{0}+q_{1}\right)}{1-b}-\frac{q_{0}^{2}+q_{1}^{2}}{2\left(1-b^{2}\right)}-\frac{b q_{0} q_{1}}{1-b^{2}}+n \frac{\left(y_{0}+b y_{1}\right) q_{0}+\left(y_{1}+b y_{0}\right) q_{1}}{1-b^{2}}+f\left(y_{0}, y_{1}\right)
$$

where $m$ denotes the income of the representative consumer and $f(\cdot, \cdot)$ represents some symmetric expectation function. In this paper, as in Hoernig [9], we suppose that $f\left(y_{0}, y_{1}\right)=-n\left(y_{0}^{2} / 2+b y_{0} y_{1}+y_{1}^{2} / 2\right) /\left(1-b^{2}\right)$. $^{6}$

We further suppose that both firms adopt identical technologies represented by cost function $C_{i}\left(q_{i}, x_{i}\right)$, where $x_{i}$ is the capacity level of firm $i \quad(i=0,1)$. Following Vives [16], Ogawa [5], Barcena-Ruiz and Garzon [6], Tomaru et al. [10], Nakamura and Saito [14], and Nakamura and Saito [15], we assume that the cost function is given by

$C_{i}\left(q_{i}, x_{i}\right)=c q_{i}+\left(q_{i}-x_{i}\right)^{2}, \quad(i=0,1) .^{7}$ This cost function implies that if each firm's output level equals its capacity level, $q_{i}=x_{i}$, then the long-run average cost is minimized. The profit of firm $i$ is given by $\Pi_{i}=p_{i} q_{i}-C_{i}\left(q_{i}, x_{i}\right)$, $(i=0,1)$. Consumer surplus as the representative consumer utility is represented as follows:

$C S=U\left(q_{0}, q_{1} ; y_{0}, y_{1}\right)-p_{0} q_{0}-p_{1} q_{1}$, whereas producer surplus is given by the sum of the profits of both firms 0 and 1 , $\pi_{0}+\pi_{1}$. Finally, we suppose that social welfare in this paper is equal to the sum of consumer surplus and producer surplus.

We investigate the game with the following two stages: In the first stage, firms 0 and 1 simultaneously set their capacity levels. In the second stage, after both the firms observe each other's capacity level, they engage in a quantitysetting competition. In the fashion of Hoernig [9], we consider the subgame perfect Nash equilibrium presented in Katz and Shapiro [8] as our equilibrium concept. Thus, in the equilibrium, we derive the subgame perfect Nash equilibrium under the additional "rational expectations" assumption: $y_{0}=q_{0}$ and $y_{1}=q_{1}$.

\section{Equilibrium Analysis}

We solve the game by backward induction from the second stage to obtain the rational expectations subgame perfect Nash equilibrium. In the second stage, firm 0 maximizes social welfare $W$ with respect to $q_{0}$, whereas firm 1 maximizes its absolute profit $\pi_{1}$ with respect to $q_{1}$. The best-response functions of both firms 0 and 1 in the second stage are given as follows:

$$
\begin{gathered}
q_{0}\left(q_{1} ; y_{0}, y_{1}, x_{0}\right)=\frac{a(1+b)-c+2 x_{0}+n y_{0}-b\left[q_{1}-b\left(c-2 x_{0}\right)-n y_{1}\right]}{3-2 b^{2}} \\
q_{1}\left(q_{0} ; y_{0}, y_{1}, x_{1}\right)=\frac{a(1+b)-c+2 x_{1}-b\left[q_{0}-b\left(c-2 x_{1}\right)-n y_{0}\right]+n y_{1}}{4-2 b^{2}}
\end{gathered}
$$

From Equations (1) and (2), we find that for any strength of network effects and degree of product differentiation, $n, q_{i}$ is decreasing in $q_{j}$, and thus the quantity levels of both firms 0 and 1 are strategic substitutes $(i, j=0,1 ; i \neq j)$.

Furthermore, we obtain the rational expectations Nash equilibrium of the quantity-setting stage by substituting the two conditions $y_{0}=q_{0}$ and $y_{1}=q_{1}$ into the best-response functions of both firms 0 and 1 . Then, we obtain

$$
\begin{gathered}
q_{0}\left(x_{0}, x_{1}\right)=\frac{(1+b)[a-(1-b) c]\left(4-b-2 b^{2}-n+b n\right)+2\left(1-b^{2}\right)\left(4-2 b^{2}-n\right) x_{0}-2 b\left(1-b^{2}\right)(1-n) x_{1}}{(4-n)(3-n)-b^{2}[15-(6-n) n]+4 b^{4}}, \\
q_{1}\left(x_{0}, x_{1}\right)=\frac{\left(1-b^{2}\right)\left[a(3+2 b-n)-(1-b) c(3+2 b-n)-2 b(1-n) x_{0}+2\left(3-2 b^{2}-n\right) x_{1}\right]}{(4-n)(3-n)-b^{2}[15-(6-n) n]+4 b^{4}} .
\end{gathered}
$$

In the first stage, both firms 0 and 1 know that their capacity choice affects their quantity levels in the second stage. Given Equations (3) and (4), firms 0 and 1 simultaneously and independently set their capacity levels with respect to social welfare and own absolute profit, respectively. Thus, by solving the first-order conditions of firms 0 and 1 in the first stage, we have

\footnotetext{
${ }^{6}$ This assumption on the form of $f(\cdot, \cdot)$ implies that the representative consumer's utility is the highest with respect to the consumption vector of the goods produced by both the public firm and private firm, $\left(q_{0}, q_{1}\right)$, when expectations are correct.

${ }^{7}$ We assume that $a /(1-b)>c \geq 0$ in order to ensure the non-negativity of all equilibrium outcomes.
} 


$$
\begin{aligned}
x_{0}= & R_{0}\left(x_{1}, b, n\right) \\
& (1+b)\left\{[ a - ( 1 - b ) c ] \left[(4-n)^{2}(3-n)-b\left(15-23 n+9 n^{2}-n^{3}\right)-b^{2}\left(83-51 n+11 n^{2}-n^{3}\right)+b^{3}\left(17-23 n+7 n^{2}-n^{3}\right)\right.\right. \\
= & \frac{\left.\left.+2 b^{4}\left(23-8 n+n^{2}\right)-4 b^{5}(1-n)+8 b^{6}\right]+2(1-b) b\left[15-23 n+9 n^{2}-n^{3}-b^{2}\left(17-23 n+7 n^{2}-n^{3}\right)+4 b^{4}(1-n)\right] x_{1}\right\}}{(1-n)\left[(4-n)^{2}(3-n)-2 b^{2}\left(49-37 n+10 n^{2}-n^{3}\right)+b^{4}\left(63-39 n+9 n^{2}-n^{3}\right)-4 b^{6}(3-n)\right]} \\
x_{1}= & R_{1}\left(x_{0} ; b, n\right) \\
= & \frac{2\left(2-3 b^{2}+b^{4}\right)\left(3-2 b^{2}-n\right)\left\{[a-(1-b) c](3+2 b-n)-2 b(1-n) x_{0}\right\}}{(3-n)^{2}\left(8-8 n+n^{2}\right)-2 b^{2}\left(78-125 n+63 n^{2}-13 n^{3}+n^{4}\right)+b^{4}\left(109-164 n+70 n^{2}-12 n^{3}+n^{4}\right)-8 b^{6}\left(3-4 n+n^{2}\right)}
\end{aligned}
$$

yielding

$$
\begin{aligned}
& x_{0}^{q} \\
& (1+b)[a-(1-b) c]\left[24-32 n+11 n^{2}-n^{3}-b\left(15-23 n+9 n^{2}-n^{3}\right)-b^{2}\left(31-39 n+11 n^{2}-n^{3}\right)\right. \\
= & \frac{\left.+2 b^{4}\left(5-6 n+n^{2}\right)-4 b^{5}(1-n)+b^{3}\left(17-23 n+7 n^{2}-n^{3}\right)\right]}{24-32 n+11 n^{2}-n^{3}-2 b^{2}\left(23-31 n+10 n^{2}-n^{3}\right)+b^{4}\left(27-35 n+9 n^{2}-n^{3}\right)-4 b^{6}(1-n)}, \\
x_{1}^{q}= & 2\left(2-3 b^{2}+b^{4}\right)[a-(1-b) c]\left(3-2 b^{2}-n\right) \\
24-32 n+11 n^{2}-n^{3}-2 b^{2}\left(23-31 n+10 n^{2}-n^{3}\right)+b^{4}\left(27-35 n+9 n^{2}-n^{3}\right)-4 b^{6}(1-n) &
\end{aligned}
$$

Note that superscript $q$ represents the subgame perfect equilibrium market outcomes with consumers' rational expectations in quantity competition. Thus, the output levels of both firms 0 and 1 in the equilibrium are given as follows:

$$
\begin{gathered}
q_{0}^{q}=\frac{[a-(1-b) c]\left[24-2 b^{3}(2-n)+b^{4}(1-n)-32 n+11 n^{2}-n^{3}-2 b^{2}\left(9-9 n+n^{2}\right)+2 b\left(3-3 n+n^{2}\right)\right]}{(1-n)\left[24+b^{4}(1-n)-32 n+11 n^{2}-n^{3}-2 b^{2}\left(9-9 n+n^{2}\right)\right]}, \\
q_{1}^{q}=\frac{\left(1-b^{2}\right)[a-(1-b) c]\left[12-7 n+n^{2}-b^{2}\left(15-6 n+n^{2}\right)+4 b^{4}\right]}{24-32 n+11 n^{2}-n^{3}-2 b^{2}\left(23-31 n+10 n^{2}-n^{3}\right)+b^{4}\left(27-35 n+9 n^{2}-n^{3}\right)-4 b^{6}(1-n)} .
\end{gathered}
$$

From easy calculations, we obtain the following results on the difference between the output and capacity levels of both firms 0 and 1 :

$$
\begin{aligned}
q_{0}^{q}-x_{0}^{q} & =\frac{b\left(1-b^{2}\right)[a+(1-b) c](1-n)}{24-32 n+11 n^{2}-n^{3}-2 b^{2}\left(23-31 n+10 n^{2}-n^{3}\right)+b^{4}\left(27-35 n+9 n^{2}-n^{3}\right)-4 b^{6}(1-n)}, \\
& >0, \quad \forall b \in(0,1) \text { and } \forall n \in[0,1) \\
q_{1}^{q}-x_{1}^{q} & =-\frac{\left(1-b^{2}\right)[a-(1-b) c]\left[(3-n) n+b^{2}\left(1-4 n+n^{2}\right)\right]}{24-32 n+11 n^{2}-n^{3}-2 b^{2}\left(23-31 n+10 n^{2}-n^{3}\right)+b^{4}\left(27-35 n+9 n^{2}-n^{3}\right)-4 b^{6}(1-n)} . \\
& <0, \quad \forall b \in(0,1) \text { and } \forall n \in[0,1)
\end{aligned}
$$

Thus, we recognize that the social welfare-maximizing public firm 0 chooses under-capacity irrespective of the strength of network effects, $n$, and demand parameter, $b$, whereas an absolute profit-maximizing private firm 1 always chooses over-capacity. By summing the above two facts, we obtain the following proposition on the differences between the quantity and capacity levels of both firms 0 and 1.

Proposition 1 Social welfare-maximizing public firm 0 chooses under-capacity, $q_{0}^{q}>x_{0}^{q}$, for any value of the de- 
mand parameter $b \in(0,1)$ and any strength of network effects $n \in[0,1)$. In contrast, absolute profit-maximizing private firm 0 chooses over-capacity, $q_{1}^{q}<x_{1}^{q}$, for any value of the demand parameter $b \in(0,1)$ and any strength of network effects $n \in[0,1)$.

Before we state the intuition behind Proposition 1, we need to confirm the strategic relation between the capacity levels of firms 0 and 1 . From easy calculations, we obtain the following results:

$$
\begin{gathered}
\frac{\partial R_{0}\left(x_{1} ; b, n\right)}{\partial x_{1}}=-\frac{2(1-b) b(1+b)\left[15-8 n+n^{2}-b^{2}\left(17-6 n+n^{2}\right)+4 b^{4}\right]}{(4-n)^{2}(3-n)-2 b^{2}\left(49-37 n+10 n^{2}-n^{3}\right)+b^{4}\left(63-39 n+9 n^{2}-n^{3}\right)-4 b^{6}(3-n)}<0, \\
\frac{\partial R_{1}\left(x_{0} ; b, n\right)}{\partial x_{0}}=-\frac{4 b\left(2-3 b^{2}+b^{4}\right)(1-n)\left(3-2 b^{2}-n\right)}{(3-n)^{2}\left(8-8 n+n^{2}\right)-2 b^{2}\left(78-125 n+63 n^{2}-13 n^{3}+n^{4}\right)+}<0 . \\
b^{4}\left(109-164 n+70 n^{2}-12 n^{3}+n^{4}\right)-8 b^{6}\left(3-4 n+n^{2}\right)
\end{gathered}
$$

Thus, we find that the capacity levels of firms 0 and 1 are strategic substitutes. First, we state the intuition on why the difference between the quantity and capacity levels of public firm 0 is always positive irrespective of both the strength of network effects $n$ and degree of product differentiation $b$. Firm 0 attempts to increase the quantity level of firm 1 in order to raise the equilibrium social welfare. Thus, the less aggressive behavior on the capacity setting of firm 0 is explained by the following two effects: 1) the negative association between the quantity level of firm 1 and the capacity level of firm 0, which is described in Equation (4), and 2) the strategic substitutability between the capacity levels of firms 0 and 1 and the positive association between the quantity and capacity levels of firm 1 . More precisely, from 1 ), firm 0 can directly increase the quantity level of firm 1 by refraining from increasing its capacity level, and from 2), firm 0 can increase the quantity of firm 1 through raising the capacity level of firm 1 by refraining from increasing its capacity level. Consequently, firm 0 always chooses under-capacity irrespective of the degree of product differentiation $b$ and strength of network effects $n$, which is strikingly different from the result that a social welfare-maximizing public firm chooses over-capacity in a price-setting mixed duopoly with network effects as considered in Nakamura [7]. In contrast, absolute profit-maximizing private firm 1 attempts to expand its market share by increasing its own capacity level through 1) the positive association between the quantity and capacity levels of firm 1 and 2) the strategic substitutability between the capacity levels of firms 0 and 1 and the negative association between the quantity level of firm 0 and the capacity level of firm 1 . This result is also different from that obtained in price competition with network effects, which was investigated in Nakamura [7]. In particular, in the case of price competition with network effects, it was shown that the difference between the quantity and capacity levels of absolute profit-maximizing private firm 1 strictly depends on both the product differentiation, $b$, and the strength of network effects, $n$. This indicates that the difference in the quantity and capacity levels of a social welfare-maximizing public firm and an absolute profit-maximizing firm strictly changes on the basis of the competition style in a duopoly with network effects.

In sum, as compared with the results on the difference between the quantity and capacity levels of both the public firm and private firm in price competition with network effects, we find that the differences between their quantity and capacity levels obtained in quantity competition are more simple. In addition, in the case of quantity competition with substitutable goods and network effects, as considered in this paper, the differences between the quantity and capacity levels of a social welfare-maximizing public firm and an absolute profit-maximizing private firm are the same as those obtained in the case of a quantity-setting mixed duopoly without any network effects as explored in Ogawa [5]. Therefore, in quantity competition with substitutable goods, the existence of a network effect à la Katz and Shapiro [8] and Hoernig [9] does not influence the difference between the quantity and capacity levels of both the social welfare- maximizing public firm and the absolute-profit maximizing private firm.

\section{Conclusions}

This paper explored the capacity choice for a public firm that is a social welfare-maximizer and a private firm that is an absolute profit-maximizer in the context of a quantity-setting mixed duopoly with network effects à la Katz and Shapiro [8] and Hoernig [9]. In price competition with network effects which was investigated in Nakamura [7], the social welfare-maximizing public firm chooses over-capacity irrespective of the strength of network effects and product differentiation and the difference between the quantity and capacity levels of the absolute profit-maximizing private firm strictly depends on both the degree of product differentiation and strength of net- 
work effects.

In contrast, in quantity competition with network effects, which we considered in this paper, the social welfare-maximizing public firm chooses under-capacity irrespective of the degree of product differentiation and strength of network effects, whereas the absolute profitmaximizing private firm chooses over-capacity irrespective of the degree of product differentiation and strength of network effects. The intuition behind these results are as follows: On the difference between the quantity and capacity levels of the social welfare-maximizing public firm, the firm attempts to increase the quantity level of the rival private firm in order to enhance social welfare. More concretely, regardless of the degree of product differentiation and strength of network effects, the social welfare-maximizing public firm tries to increase the quantity level of the private firm by refraining from increasing its own capacity level, directly through the negative association between the quantity level of the private firm and its own capacity and indirectly through the strategic substitutability between the capacity levels of the firms and the positive association between the quantity and capacity levels of the private firm. In addition, the private firm tends to increase its capacity level through the positive association between its quantity and capacity levels, and through the combination of the strategic substitutability between the capacity levels of both the firms and the positive association between its own quantity and capacity levels in order to be competitive with the social welfare-maximizing public firm, implying that the private firm chooses over-capacity regardless of the degree of product differentiation and strength of network effects.

Finally, we mention an open problem that we need to tackle in the future. Throughout this paper, we considered the absolute profit as the objective of a private firm. In some sort of new papers, we should explore the results on the capacity choice issues between social welfaremaximizing public firms and absolute profit-maximizing private firms on the basis of the strength of network effects and degree of product differentiation under the assumption that the objective function of the private firms is its relative profit.

\section{Acknowledgements}

Nakamura thanks the financial support by KAKENHI (25870113). All remaining errors are our own.

\section{REFERENCES}

[1] A. Dixit, "The Role of Investment in Entry Deterrence," Economic Journal, Vol. 90, No. 357, 2008, pp. 95-106. http://dx.doi.org/10.2307/2231658

[2] J. A. Brander and B. J. Spencer, "Strategic Commitment with R\&D: The Symmetric Case," Bell Journal of Economics, Vol. 14, No. 1, 1983, pp. 225-235. http://dx.doi.org/10.2307/3003549

[3] A. Nishimori and H. Ogawa, "Do Firms always Choose Excess Capacity?” Economics Bulletin, Vol. 12, No. 2, 2004, pp. 1-7.

[4] Y. Horiba and S. Tsutsui, "International Duopoly, Tariff Policies and the Case of Free Trade," Japanese Economic Review, Vol. 51, No. 2, 2009, pp. 207-220. http://dx.doi.org/10.1111/1468-5876.00147

[5] H. Ogawa, "Capacity Choice in the Mixed Duopoly with Product Differentiation,” Economics Bulletin, Vol. 12, No. 8, 2006, pp. 1-6.

[6] J. C. Bárcena-Ruiz and M. B. Garzón, "Capacity Choice in a Mixed Duopoly under Price Competition,” Economics Bulletin, Vol. 12, No. 26, 2007, pp. 1-7.

[7] Y. Nakamura, "Capacity Choice in a Price-Setting Mixed Duopoly with Network Effects,” Modern Economy, Vol. 4, No. 5, 2013, pp. 418-425. http://dx.doi.org/10.4236/me.2013.45044

[8] M. Katz and C. Shapiro, "Network Externalities, Competition, and Compatibility," American Economic Review, Vol. 75, No. 3, 1985, pp. 424-440.

[9] S. Hoernig, "Strategic Delegation under Price Competition and Network Effects," Economics Letters, Vol. 117, No. 2, 2012, pp. 487-489.

http://dx.doi.org/10.1016/j.econlet.2012.06.045

[10] Y. Tomaru, Y. Nakamura and M. Saito, "Capacity Choice in a Mixed Duopoly with Managerial Delegation," Economics Bulletin, Vol. 29, No. 3, 2009, pp. 1904-1924.

[11] C. Fershtman and K. Judd, "Equilibrium Incentives in Oligopoly,” American Economic Review, Vol. 77, No. 5, 1987, pp. 927-940.

[12] S. D. Sklivas, "The Strategic Choice of Management Incentives,” RAND Journal of Economics, Vol. 18, 1987, pp. 452-458. http://dx.doi.org/10.2307/2555609

[13] J. Vickers, "Delagation and the Theory of the Firm," Economic Journal, Vol. 95, 1985, pp. 138-147. http://dx.doi.org/10.2307/2232877

[14] Y. Nakamura and M. Saito, "Capacity Choice in a Mixed Duopoly: The Relative Performance Approach," Theoretical Economics Letters, Vol. 3, No. 2, 2013, pp. 124133. http://dx.doi.org/10.4236/tel.2013.32020

[15] Y. Nakamura and M. Saito, "Capacity Choice in a PriceSetting Mixed Duopoly: The Relative Performance Approach," Modern Economy, Vol. 4, No. 4, 2013, pp. 273280. http://dx.doi.org/10.4236/me.2013.44031

[16] X. Vives, "Commitment, Flexibility, and Market Outcomes,” International Journal of Industrial Organization, Vol. 4, No. 2, 1986, pp. 217-229. http://dx.doi.org/10.1016/0167-7187(86)90032-9 